\title{
The factors associated with transient hypothyroxinemia of prematurity
}

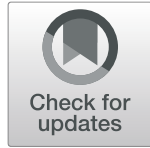

\author{
Aslan Yilmaz ${ }^{*}$, Yavuz Ozer ${ }^{2}$, Nesrin Kaya ${ }^{1}$, Hande Turan², Hazal Cansu Acar ${ }^{3}$, Oya Ercan², Yildiz Perk', \\ Olcay Evliyaoglu² and Mehmet Vural ${ }^{1}$
}

\begin{abstract}
Background: Hypothyroxinemia is defined by low levels of thyroxine (T4) despite low or normal levels of thyroidstimulating hormone (TSH). This study aimed to evaluate the factors associated with transient hypothyroxinemia of prematurity (THOP) in newborns admitted to the neonatal intensive care unit (NICU).

Method: This is a single center, retrospective, case-control study. Premature newborns, between 24 and 34 weeks of gestation, hospitalised between January 2014-December 2019 in Istanbul University-Cerrahpasa Faculty of Medicine NICU were analyzed through their medical records. Thyroid function tests were routinely performed between the 10th and 20th days of postnatal life and were evaluated according to the gestational age references. Thirty six possible associated factors (prenatal and postnatal parameters, medical treatments, clinical diagnoses and applications in NICU) were searched in the patient group with THOP $(n=71)$ and the control group with euthyroid prematures $(n=73)$. The factors for THOP were identified by univariate analysis, followed by multivariate analysis.

Results: Mean gestational ages of the study and the control groups were $29.7 \pm 2.48$ and $30.5 \pm 2.30$ weeks, respectively $(p=0.606)$. The birth weight, small for gestational age (SGA), intraventricular hemorrhage (IVH), congenital heart disease (CHD) were found to be the possible associated factors for THOP in the univariate analysis and CHD ( $p=0.007$, odds ratio [OR]:4.9, 95\% confidence interval [Cl]: 1.5-15.8), BW ( $p=0.004$, OR:0.999, 95\% Cl: 0.91.0) and SGA ( $p=0.010$, OR:4.6, $95 \%$ Cl: $1.4-14.7)$ were found to be factors associated with THOP determined by univariate logistic regression analysis.
\end{abstract}

Conclusıons: Although some treatment practices might have had direct effects on pituitary-thyroid axis, related with the severity of the newborn clinical conditions, non of them was found to be a associated factor for THOP. However, CHD and SGA may be considered as associated factors with THOP detected in preterm infants.

Keywords: Newborn, Preterm, Hypothyroxinemia, Thyroid, Small for gestational age, Congenital heart disease

\section{Background}

Transient hypothyroxinemia of prematurity (THOP) is defined by low levels of thyroxine (T4) despite low or normal levels of thyroid-stimulating hormone (TSH) [1]. Hypothyroxinemia is observed in around $50 \%$ of premature newborns and its risk increases as the gestational

\footnotetext{
* Correspondence: draslanyilmaz@hotmail.com

'Department of Neonatology, Cerrahpasa Faculty of Medicine, Istanbul University-Cerrahpasa, Kocamustafapasa, Fatih, 34098 Istanbul, Turkey

Full list of author information is available at the end of the article
}

week decreases [2, 3]. Serum T4 and free T4 (FT4) levels in premature newborns vary according to gestational age in the first days of life. T4 and FT4 concentrations decline to the lowest level between ten and fourteenth days after birth. This situation is more severe with low gestational week and birth weight (BW) [4]. In term infants (37-42 weeks' gestation) serum T4 levels characteristically increase in the first week of life whereas in infants born prematurely, and especially those below 30 weeks'

(c) The Author(s). 2021 Open Access This article is licensed under a Creative Commons Attribution 4.0 International License, which permits use, sharing, adaptation, distribution and reproduction in any medium or format, as long as you give appropriate credit to the original author(s) and the source, provide a link to the Creative Commons licence, and indicate if changes were made. The images or other third party material in this article are included in the article's Creative Commons licence, unless indicated otherwise in a credit line to the material. If material is not included in the article's Creative Commons licence and your intended use is not permitted by statutory regulation or exceeds the permitted use, you will need to obtain permission directly from the copyright holder. To view a copy of this licence, visit http://creativecommons.org/licenses/by/4.0/. The Creative Commons Public Domain Dedication waiver (http://creativecommons.org/publicdomain/zero/1.0/) applies to the data made available in this article, unless otherwise stated in a credit line to the data. 
gestation, may decrease transiently resulting in a period of hypothyroxinaemia $[5,6]$.

TSH screening is the most sensitive test for primary $\mathrm{CH}$ detection. However, a unique form of $\mathrm{CH}$ characterized by a delayed TSH elevation has been described in preterm infants [2]. The screening programme may not identify $\mathrm{CH}$ in premature infants due to delayed TSH elavation, therefore, rescreening is recommended for all preterm infants by Europen Society for Pediatric Endocrinology, on behalf of all pediatric endocrinologist societies worldwide [7]. Continuing debate exists regarding whether THOP is harmful to the developing brain. While there are studies showing the benefit of levothyroxine (L-T4) treatment, there are also studies reporting that the treatment does not make differences or even causes worse neurodevelopmental outcomes [8]. Although treatment of hypothyroxinemia is recommended in newborns below 28 week of gestational age (GA), there is currently no concencus on this issue [9]. In a recent randomized controlled study conducted by May et al., premature babies born earlier than 28 wk. were divided into two groups and one group was given thyroxine from the first days, and the control group was not given any treatment. Motor, language, and cognitive functions were found to be significantly higher in Bayley III development tests performed at 42 months in the group that received the thyroxine treatment [10].

Postpartum TSH and thyroid hormone peaks observed in term newborns are not so evident in preterms. Especially below 30 weeks' gestation, TSH increase is late and weak, while T4 and FT4 levels remain low [11]. In premature newborns, physiologicaly low thyroid hormones can be explained by: blunted phsyiolgic hyperthyroidim (correlated with gestational age), increase of thyroid hormone demand (thermogenesis, cardiac and skeletal muscle functions), deficiencies in iodine metabolism, immaturity of hypothalamo-pituitary-thyroid axis, insufficient response of thyroid gland to TRH, low T4 conversion from $\mathrm{T} 3$ and early interruption of maternal T4 transport $[12,13]$. In addition to these factors, thyroid functions may also be suppressed due to medications that are commonly used in premature infants (dopamine, dexamethasone), disorders, such as respiratory distress syndrome, infections, necrotizing enterocolitis, patent ductus arteriosus, malnutrition, chorioamnionitis, as well as iodine deficiency or excess [12, 14-16]. Thus THOP can be observed due to multiple factors in premature newborns. This study aimed to evaluate the factors associated with THOP.

\section{Method}

\section{Participants and Datas}

This is a single center, retrospective, case-control study. The THOP and control groups (euthyroid) of premature newborns with similar gestational age and closest date of birth time were compared. File records of 538 newborns who had been admitted to Istanbul UniversityCerrahpasa Faculty of Medicine Neonatal Intensive Care Unit (NICU) between January 2014-December 2019 were retrospectively analyzed. Recruitment criteria: premature newborns between 24 and 34 GA, without multiple major congenital anomaly and whose serum thyroid function test were done between the 10th and 20th days of postnatal life. Cases with major multiple organ anomalies excluded from the study (two cases had hydrops fetalis, one case had trisomy 18 , two cases had multiple extremity anomalies and ventriculomegaly, two cases had kidney and cardiac anomalies).

During this 5-year retrospective study: THOP, euthyroid, primary hypothyroidism and subclinical hypothyroidism were diagnosed in $45.8 \%(n=83), 47.5 \%$ $(n=86), 4.9 \%(n=9)$ and $1.6 \%(n=3)$, respectively. Infants of mothers with maternal hypothyrodism, pregnancy without follow-up was excluded from both THOP and euthyroid groups. Two groups were formed as the patient group $(n=71$, THOP) and the control group ( $n=73$, euthyroid). The study design was planned as shown in Fig. 1.

Thirty six possible associated factors detected between birth to the time of blood samples collection (prenatal and postnatal parameters, medical treatments, clinical diagnoses and applications in NICU) were compared between the patient group with THOP $(n=71)$ and the control group with euthyroid infants $(n=73)$. Data including applied medical treatments and clinical applications were collected from the date of birth to the measurement of TSH and FT4.

Ethics approval was obtained from Istanbul UniversityCerrahpaşa Faculty of Medicine Ethics Committee (reference no: 36423).

\section{Definitions}

Serum free thyroxine (FT4) and TSH levels were measured using commercially available kits (Roche Elecys 2010, USA) by electrochemiluminescence (ECLIA) method. The thyroid hormone levels were assessed based on the weeks' gestational and postnatal age references. In the second postnatal week following intervals were accepted to be the normal range for FT4: $1.45 \pm 0.5 \mathrm{ng} / \mathrm{dl}$ for $23-27$ week, $1.65 \pm 0.4 \mathrm{ng} / \mathrm{dl}$ for $28-$ 30 week, $1.98 \pm 0.4 \mathrm{ng} / \mathrm{dl}$ for $31-34$ week and the normal range for serum TSH: $3.9 \pm 2.7 \mathrm{mU} / \mathrm{L}$ for $23-27$ week, $4.9 \pm 11.2 \mathrm{mU} / \mathrm{L}$ for $28-30$ week, $3.8 \pm 9.3 \mathrm{mU} / \mathrm{L}$ for $31-$ 34 week were taken [1]. THOP was defined as a low FT4 (as per the age reference interval) and low or normal TSH (as per the age reference interval) levels [8]. Serum TSH and FT4 measurements were performed between the 10th and 20th days of postnatal life. 


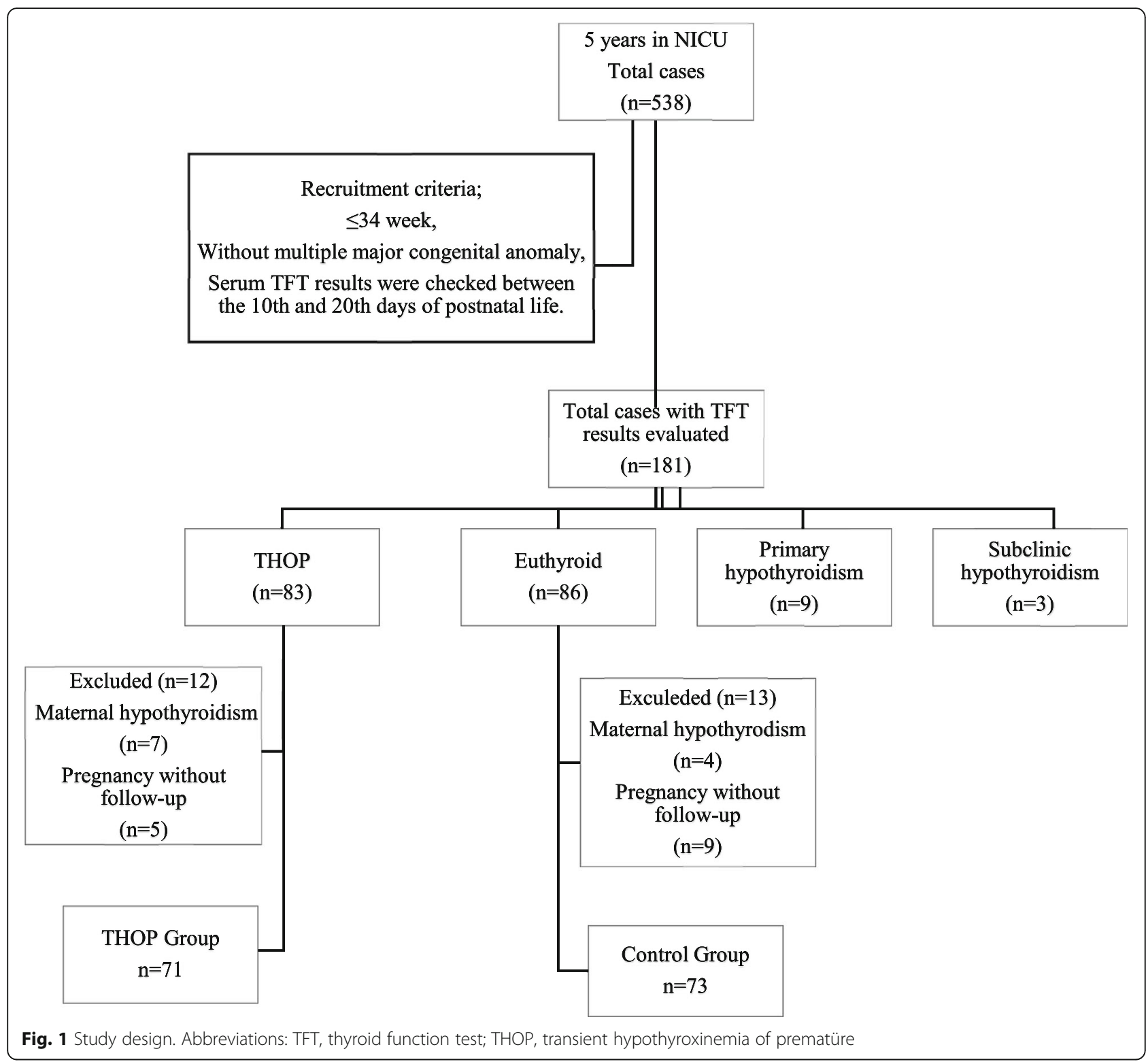

Bronchopulmonary dysplasia (BPD) was defined as the development of concomitant parenchymal lung injury requiring treatment with oxygen $>21 \%$ and/or positive pressure at postmenstrual gestational age at 36 weeks or at postnatal 56 days or at discharge (which one is earlier) [17]. Echocardiography evaluation was performed by pediatric cardiologist, patent ductus arteriosus (PDA), and other congenital heart diseases (CHD) were recorded. In our practice, both clinical findings and echocardiographic measurements were used to diagnose a hemodynamically significant PDA [18]. Respiratory Distress Syndrome (RDS) was diagnosed in infants who with signs in the chest radiograph (low lung volumes and reticulogranular appearance in the lung fields, with or without air bronchograms) and in those requiring oxygen to maintain target saturation, requiring surfactant treatment. Premature newborns who received mechanical ventilation or non-invasive ventilation support for more than $24 \mathrm{~h}$ were considered to receive ventilation support. Sepsis was diagnosed with positive blood cultures. Severe intraventricular hemorrhage (IVH) was defined as grade 3 or 4, while the presence of severe retinopathy of prematurity (ROP) was defined as grade 3 and beyond based on the International ROP classification [19, 20]. Fetal growth restriction (FGR) is defined as the failure of the fetus to achieve its genetically determined growth potential [21]. The cases whose weight was below the 10th percentile in antenatal percentile follow-ups were defined as FGR by a specialist in perinatology. Small for gestational age (SGA) is defined 
by birth weight below the 10th percentile for gestational age [22]. Central catheterisation was performed in two ways: umbilical arterial/venous cathether and Peripherally Inserted Central Catheter (PICC).

\section{Statistical methods}

The SPSS v.21 (SPSS Inc., Chicago, IL, USA) software was used for the statistical analyzes. The compatibility of the data with normal distribution was evaluated by the descriptive statistics (mean, standard deviation) and Kolmogorov Smirnov Test. Continuous variables were shown with mean \pm standart deviation and median (25th - 75th quarters), and categorical variables with frequency and percentage (\%). The Mann-Whitney $U$ test was used to compare the groups in terms of continuous variables. The Chi-squared test and Fisher's exact test were used, where appropriate, in the analysis of the categorical variables. Possible associated factors with THOP which have $p<0.2$ were included in univariate logistic regression analysis. The results were given as the Odds Ratio (OR) and 95\% confidence intervals (95\% CI). The level of significance was taken as $p<0.05$.

\section{Results}

Characteristics of the THOP and control groups are presented in Table 1. As expected, the FT4 levels were lower in the THOP than the control group $(1.00 \pm 0.24$ and $1.55 \pm 0.28 \mathrm{ng} / \mathrm{dl}$, respectively) $(p<0.001)$, while there was no significant difference between the TSH levels $(4.76 \pm 3.36$ and $4.32 \pm 2.60 \mathrm{mU} / \mathrm{L}$, respectively) $(p=0.556)$. Mean birth weight was lower in the THOP group $(1306,52 \pm 446,44 \mathrm{~g})$ compared to the control group $(1544,93 \pm 498,64 \mathrm{~g})(p<0.001)$ (Table 2).

In the THOP group, a total of 15 cases of CHD; 8 cases of atrial septal defect (ASD), 3 cases of ventricular septal defect (VSD), 1 case of transposition of the great arteries (TGA), 1 case of coarctation of the aorta (CoA), 1 case of atrial septal aneurysm, 1 case of mitral valve prolapse were detected. In the control group, 4 patients had ASD and 1 VSD. In THOP group, CHD was statistically significantly higher than control group $(p=0.018$, Table 2$)$.

When 36 associated factors were compared between the THOP patients and the control group in univariate analysis: 5th minute Apgar scores, delivery type, FGR, in vitro fertilization (IVF), maternal smoking, gestational hypertension and diabetes, prenatal betamethasone treatments, central catheterisations, sepsis, pneumothorax, PDA, drug history (vancomycin+amikacin, ampicillin+gentamisin, caffeine, dopamine, dobutamine, fentanyl, midazolam, paracetamol, ibuprofen, fluconazole), phototherapy, development of hypoglycemia, RDS, BPD and ROP, erythrocyte suspension (ES), thrombocyte suspension (TS) and fresh frozen plasma transfusions, mechanical ventilator and noninvasive ventilation support were not statistically significant (Table 2). BW was lower and incidences of IVH, SGA and CHD were higher in the THOP group $(p<0.05$, Table 2). Possible associated factors with THOP which have $p<0.2$ were included in univariate logistic regression analysis (fetal growth retardation, gestational diabetes, 5th minute Apgar score, BW, SGA, dobutamine, ibuprofen, IVH, bronchopulmonary dysplasia, CHD) $(p<0.200)$ were analyzed. The CHD $(p=0.007$, odds ratio [OR]:4.9, 95\% confidence interval [CI]: 1.5-15.8), BW $(p=0.004$, OR: $0.999,95 \%$ CI: $0.9-1.0)$ and SGA ( $p=0.010$, OR:4.6, 95\% CI: 1.4-14.7) were found to be factors associated with THOP $(p<0.05$, Table 3$)$. As seen in the Table 3 , the risk of THOP was found to be increased 4.9 and 4.6 times more in premature infants diagnosed with CHD and SGA, respectively. It was also determined that each one houndred gram increase in BW reduced the THOP risk by $10 \%$ (Table 3).

\section{Discussion}

In this study, The THOP and control groups (euthyroid) of premature newborns born at the same time and with the most similar gestational age were compared. Low birth weight, SGA and CHD were found to be as associated factors with THOP. These three associated factors are not affected by the gestational age, the severity of the

Table 1 Demographic Features and Laboratory Findings of THOP Patients and Controls

\begin{tabular}{|c|c|c|c|}
\hline & THOP group & Control group & $P$ value \\
\hline Participants, n & 71 & 73 & \\
\hline Male gender & $41(58)$ & $34(47)$ & 0.180 \\
\hline GA (wk) & $29.7 \pm 2.48(24-34)$ & $30.5 \pm 2.30(26-34)$ & 0.606 \\
\hline Measurement day & $11.9 \pm 2.22(10-20)$ & $12.3 \pm 2.92(10-20)$ & 0.948 \\
\hline Measurement GAA (wk) & $31.4 \pm 2.42(26-36)$ & $32.2 \pm 2.18(28-36)$ & 0.064 \\
\hline $\mathrm{FT} 4$ (ng/dl) & $1.00 \pm 0.24(0.31-1.58)$ & $1.55 \pm 0.28(0.97-2.54)$ & $<0.001$ \\
\hline $\mathrm{TSH}(\mathrm{mU} / \mathrm{L})$ & $4.76 \pm 3.36(0.25-10.64)$ & $4.32 \pm 2.60(0.73-13.3)$ & 0.556 \\
\hline
\end{tabular}

Data are given as numbers and (\%), after decimal rounded to the greater side. Other data are given as mean \pm standard deviation (min-max). When the THOP group and control group cases were compared, FT4 was lower as expected ( $p<0.05$, dark stained)

Abbreviations: THOP transient hypothyroxinemia of prematüre; GA gestational age; GAA gestation-adjusted age 
Table 2 Comparison of possible associated factors with THOP between patients and controls

\begin{tabular}{|c|c|c|c|}
\hline Risk factors & THOP group & Control group & $P$ value \\
\hline Participants, (n) & 71 & 73 & \\
\hline BW (g) & $1306,52 \pm 446$ & $1544,93 \pm 498$ & $<0.001$ \\
\hline Apgar score < 7 (5th minute) & $34(48)$ & $24(33)$ & 0.066 \\
\hline Apgar score $\geq 7$ (5th minute) & $37(52)$ & $49(67)$ & \\
\hline Delivery type (C/S) & $63(89)$ & $67(92)$ & 0.537 \\
\hline FGR & $19(27)$ & $12(16)$ & 0.132 \\
\hline SGA & $15(21)$ & $4(5)$ & 0.006 \\
\hline \multicolumn{4}{|l|}{ PRENATAL } \\
\hline Maternal smoking & $5(7)$ & $5(7)$ & 1.000 \\
\hline IVF & $8(11)$ & $7(10)$ & 0.955 \\
\hline GDM & $6(9)$ & $13(18)$ & 0.097 \\
\hline Gestational hypertension & $20(28)$ & $21(29)$ & 1.000 \\
\hline Prenatal betamethasone treatment & $47(66)$ & $48(66)$ & 1.000 \\
\hline \multicolumn{4}{|l|}{ MEDICINE } \\
\hline Vancomycin+amikacin & $9(13)$ & $5(7)$ & 0.238 \\
\hline Ampicillin+gentamicin & $36(51)$ & $41(56)$ & 0.511 \\
\hline Surfactant & $39(55)$ & $34(46)$ & 0.403 \\
\hline Caffeine & $59(83)$ & $57(78)$ & 0.582 \\
\hline Dobutamine & $8(11)$ & $3(4)$ & 0.106 \\
\hline Dopamine & $17(24)$ & $13(18)$ & 0.365 \\
\hline Midazolam & $23(32)$ & $21(29)$ & 0.637 \\
\hline Fentanyl & $4(6)$ & $2(3)$ & 0.385 \\
\hline Paracetamol & $3(4)$ & $2(3)$ & 0.679 \\
\hline Ibuprofen & $9(13)$ & $4(6)$ & 0,132 \\
\hline Fluconazole prophylaxis & $34(48)$ & $32(44)$ & 0.626 \\
\hline \multicolumn{4}{|l|}{ CLINICAL-DIAGNOSIS } \\
\hline RDS & $39(55)$ & $34(56)$ & 0.403 \\
\hline IVH & $24(34)$ & $12(16)$ & 0.022 \\
\hline Pneumothorax & $3(4)$ & $4(5)$ & 0.726 \\
\hline PDA & $12 / 59(20)^{*}$ & $6 / 57(11)^{*}$ & 0.144 \\
\hline $\mathrm{CHD}$ & $15 / 59(25)^{*}$ & $5 / 57(9)^{*}$ & 0.018 \\
\hline ROP & $3(4)$ & $1(1)$ & 0.448 \\
\hline $\mathrm{BPD}$ & $26(37)$ & $16(22)$ & 0.052 \\
\hline Hypoglycemia & $21(30)$ & $23(31)$ & 0.802 \\
\hline Sepsis & $7(10)$ & $9(12)$ & 0.837 \\
\hline \multicolumn{4}{|l|}{ TRANSFUSIONS } \\
\hline ES transfusion & $18(25)$ & $13(18)$ & 0.271 \\
\hline TS transfusion & $5(7)$ & $5(7)$ & 0.964 \\
\hline FFP transfusion & $23(32)$ & $19(26)$ & 0.401 \\
\hline \multicolumn{4}{|l|}{ CLINICAL APPLICATIONS } \\
\hline Phototherapy & $66(93)$ & $68(93)$ & 0.964 \\
\hline Central catheter & $57(80)$ & $57(78)$ & 0.905 \\
\hline Ventilator support & $31(43)$ & $28(38)$ & 0.517 \\
\hline NIV support & $48(68)$ & $54(74)$ & 0.511 \\
\hline
\end{tabular}

Data are given as numbers and (\%), after decimal rounded to the greater side. Parameters with $p<0.2$ were included in univariate logistic regression analysis (dark stained ones)

*Data are given as cases / total cases with echocardiographic examination

Abbreviations: THOP transient hypothyroxinemia of prematüre; $B W$ birth weight; $C / S$ caesarean; FGR fetal growth retardation; SGA small for gestational age; IVF in vitro fertilization; GDM gestational diabetes; IVH intraventricular hemorrhage; PDA patent ductus arteriosus; CHD congenital heart disease; ROP premature retinopathy; BPD bronkopulmonary dysplasia; ES erirtosit suspension; TS thrombcyte suspension; FFP fresh frozen plasma; NIV non invasive ventilation 
Table 3 Factors associated with THOP determined by univariate logistic regression analysis

\begin{tabular}{llll}
\hline Factors & $\boldsymbol{P}$ Value & OR & $\mathbf{9 5 \% ~ C l}$ \\
\hline FGR (Ref. Absent) & 0.135 & 1.857 & $0.825-4.183$ \\
GDM (Ref. Absent) & 0.104 & 0.426 & $0.152-1.192$ \\
Apgar score, 5th min. (Ref. $\geq$ 7) & 0.068 & 1.876 & $0.955-3.684$ \\
Birth weight (gram) & $\mathbf{0 . 0 0 4}$ & 0.999 & $0.998-1.000$ \\
SGA (Ref. Absent) & $\mathbf{0 . 0 1 0}$ & 4.621 & $1.452-14.708$ \\
Dobutamine (Ref. Absent) & 0.120 & 2.963 & $0.753-11.659$ \\
Ibuprofen (Ref. Absent) & 0.142 & 2.504 & $0.734-8.539$ \\
IVH (Ref. Absent) & 0.178 & 1.829 & $0.776-4.356$ \\
BPD (Ref. Absent) & 0.054 & 2.058 & $0.987-4.294$ \\
CHD (Ref. Absent) & $\mathbf{0 . 0 0 7}$ & 4.930 & $1.535-15.840$ \\
PDA (Ref. Absent) & 0.151 & 2.170 & $0.754-6.246$ \\
\hline
\end{tabular}

Birth weight, SGA and detection of CHD were found to be statistically significant ( $p<0.05$, dark stained ones)

Abbreviations: FGR fetal growth retardation; GDM gestational diabetes; $B W$ birth weight; $S G A$ small for gestational age; $I V H$ intraventricular hemorrhage; $B P D$ bronkopulmonary dysplasia; $C H D$ congenital heart disease; Ref reference category

illness and the medical and clinical treatment practices applied. It is already shown in the literature that the frequency of hypothyroxinemia changes in proportion to gestational age [23]. Especially in sick infants, if hypothyroxinemia is not noticed and followed up, it may be missed in TSH screening for congenital hypothyroidism [16]. In addition, in a recent randomized and controlled study by May et al., showed a better neurological development in preterm infants under 28 weeks of gestation who had a hypothyroxinemia and who received a treatment [10]. Therefore, timely recognition and follow-up of transient hypothyroxinemia in preterm infants is important.

\section{THOP and SGA}

In our study, interestingly although THOP group had similiar gestational age with the control group, had a low birth weight in THOP group. Consequently in this study, incidence of SGA was higher in the THOP group and increased the risk of the THOP 4.6 times. Each one hundred gram increase in BW reduced the THOP risk by $10 \%$. We speculate that being SGA may result in further deficit in storage and adaptive mechanisms. A recent study by Chunhua et al., supported our results that SGA in preterms may be associated with thyroid dysfunction [24]. A comprehensive study by Bagnoli et al. showed that similar to our results, preterm SGA neonates had lower FT4 compared to preterm AGAs and TSH levels were similar [25]. It is generaly accepted that hypothyroxinemia is usually transient in preterm SGAs and is caused by placental hypoxia and delayed maturation of the thyroid gland [26]. In addition, some studies underlined that hypothyroxinemia in preterm SGAs might be attributed to nutritional deficiency and might be reversible with the regulation of nutrition [27, 28]. Similar to the literature, the results of our study suggested that thyroid function tests should be followed more closely in both preterm and SGA newborns.

\section{THOP and CHD}

It is already shown that thyroid and cardiac disorders can be associated [29]. Congenital heart diseases (5.5\%) are frequently associated with congenital hypothyroidism sugggesting common genetic mechanisms involved in thyroid and heart development [30]. The association of $\mathrm{CHD}$ and thyroid disorder in Down syndrome, which is a genetic disorder, has been well defined [31]. In the recent study of $\mathrm{HJ}$ Lee et al., it was found that the coexistence of CHD and transient thyroid disorders is approximately 50\% [32]. In a study with 76 preterm infants hospitalized in neonatal units, cardiovascular disease was significantly higher in THOP [33]. In a comprehensive study by Sadia Malik et al., evaluating the relationship between SGA and CHD, CHD was found to be twice as high in infants with SGA compared to the control group [34]. Decreased birth weight, SGA and CHD may have common pathogenetic mechansims that are associated with THOP. Similarly, in this study, hypothyroxinemia was found with a higher rate in preterms with SGA and CHD. It is well known in the literature that the combination of CHD and SGA increases mortality and morbidity [35]. Therefore, close follow-up of thyroid function tests is more important in preterms with CHD and SGA.

\section{THOP and prenatal-postnal conditions}

Some studies have shown that in preterms thyroid functions are affected by postpartum drugs and some perinatal conditions. Drugs frequently used in premature infants (dopamine, dexamethasone), respiratory distress syndrome, infections, disorders such as necrotizing enterocolitis, patent ductus arteriosus, malnutrition, chorioamnionitis, iodine deficiency or overload may suppress thyroid functions [23, 36-39]. It should be noted that gestational age is inversely correlated with the severity of problems in the premature newborns which may be associated with more intense medical and invasive treatments. Thus, it is difficult to evaluate whether an associated factor is the consequence of immaturity or the medical treament. Previous studies reported that surfactant, dopamine, glucocorticoids and erythrocyte transfusion increase the risk of THOP [40-43]. Most of these studies evaluating the associated factors for hypothyroxinemia belong to the past years and are studies with a smaller number of cases compared to our study.

The medications are used widely as gestational age decrease and severity of the disorder increases. In a study with very low birth weight newborns, it was shown that 
the negative effect of dopamine and dobutamine use on thyroid function rapidly resolved after treatment was discontinued [44]. There are some studies showing that the suppression of thyroid functions has decreased in parallel with the decrease in RDS severity due to the development of prenatal care, especially the widespread use of antenatal steroids and early surfactant treatment in recent years [23]. In a study by Lay et al., no relationship was shown between THOP and PDA, IVH, antenatal steroid use, ROP, Apgar scores, and sepsis [4]. In different pathologies like respiratory distress syndrome, PDA, sepsis, intracranial hemorrhage and necrotizing enterocolitis, it is claimed that their effects on serum thyroid hormone levels are mediated in part by acute inflammatory cytokines [23]. In our study, differently from previous studies RDS, PDA, sepsis, IVH, dopamine, dobutamine and erythrocyte suspension transfusion were not found to be the associated factors for THOP. The reason for these different results in our study, may be due to less needed treatments and their temporary effects with the widespread use of surfactants and antenatal steroids in recent years and the decrease in the severity of diseases in neonatal units.

In this study, serum TFT results between ten and twenty days of life were evaluated according to the postnatal and gestational age reference values (1). However, there is no TFT level defined as "low or normal" and there is no consensus on the timing of measurements. The strength of this study is that it is one of the few studies [11, 14, 40-44] evaluating so many parameters associated with THOP in premature newborns. On the other hand our study have some limitations as being a single center and retrospective study. A multi center and prospective study could create more meaningful results.

In conclusion, although some treatment practices could have direct effects on the pituitary-thyroid axis in relation to the severity of neonatal clinical conditions, none of these were found to be an associated factor with THOP in our study. CHD and SGA were found to be as associated factors with THOP.

\begin{abstract}
Abbreviations
THOP: transient hypothyroxinemia of prematüre; BW: birth weight; C/ S: caesarean; FGR: fetal growth retardation; SGA: small for gestational age; IVF: in vitro fertilization; GDM: gestational diabetes; IVH: intraventricular hemorrhage; PDA: patent ductus arteriosus; CHD: congenital heart disease; ROP: premature retinopathy; BPD: bronkopulmonary dysplasia; ES: erirtosit suspension; TS: thrombcyte suspension; FFP: fresh frozen plasma; NIV: non invasive ventilation
\end{abstract}

\section{Acknowledgements}

Not applicable.

\section{Authors' contributions}

The authors declare that they have no competing interests. AY developed the theory, designed the model and the computational framework and analysed the data, prepared tables, the writing of the manuscript. YÖ performed the analytic calculations and performed the numerical simulations. NK and HT provided critical feedback. HCA analysed the data, provided critical feedback. O. Ercan and YP followed the patients clinically, provided critical feedback. O. Evliyaoglu supervised the project, provided critical feedback the main conceptual ideas and proof outline, the writing of the manuscript. MV supervised the project, the main conceptual ideas and proof outline, the writing of the manuscript. All authors reviewed the manuscript. No form of payment was given to anyone to produce the manuscript. The author(s) read and approved the final manuscript.

Funding

There is no funding.

\section{Availability of data and materials}

The datasets generated and/or analysed during the current study are not publicly available due to our hospital policy but are available from the corresponding author on reasonable request.

\section{Declarations}

Ethics approval and consent to participate

Ethics approval was obtained from Istanbul University-Cerrahpaşa Faculty of Medicine Ethics Committee and performed in accordance with the tenets of the Declaration of Helsinki. Informed consent was obtained from parent and/ or legal guardian as participants are under 16 years of age.

\section{Consent for publication}

Not applicable.

\section{Competing interests}

The authors declare that they have no competing interests.

\section{Author details}

'Department of Neonatology, Cerrahpasa Faculty of Medicine, Istanbul University-Cerrahpasa, Kocamustafapasa, Fatih, 34098 Istanbul, Turkey. ${ }^{2}$ Department of Pediatric Endocrinology, Cerrahpasa Faculty of Medicine, Istanbul University-Cerrahpasa, Kocamustafapasa, Fatih, 34098 Istanbul, Turkey. ${ }^{3}$ Department of Public Health, Cerrahpasa Faculty of Medicine, Istanbul University-Cerrahpasa, Kocamustafapasa, Fatih, 34098 Istanbul, Turkey.

Received: 22 April 2021 Accepted: 25 July 2021

Published online: 14 August 2021

\section{References}

1. Williams FLR, et al. Developmental trends in cord and postpartum serum thyroid hormones in preterm infants. J Clin Endocrinol Metab. 2004;89(11): 5314-20. https://doi.org/10.1210/jc.2004-0869.

2. Chung HR. Screening and management of thyroid dysfunction in preterm infants. Ann Pediatr Endocrinol Metab. 2019;24(1):15.

3. Gamma L, Edmund F, et al. Phase 1 trial of 4 thyroid hormone regimens for transient hypothyroxinemia in neonates of $<28$ weeks' gestation. Pediatrics. 2009;124(2):e258-68. https://doi.org/10.1542/peds.2008-2837.

4. Tan LO, Tan MG, Poon WB. Lack of association between hypothyroxinemia of prematurity and transient thyroid abnormalities with adverse long term neurodevelopmental outcome in very low birth weight infants. PLOS ONE. 2019;14(9)::0222018.

5. Van Vliet G, Deladoëy J. Disorders of the thyroid in the newborn and infant. Pediatr Endocrinol. 2014:186-208.

6. Rose SR, et al. Update of newborn screening and therapy for congenital hypothyroidism. Pediatrics. 2006;117(6):2290-303. https://doi.org/10.1542/ peds.2006-0915.

7. Léger J, Olivieri A, Donaldson M, Torresani T, Krude H, van Vliet G, et al. European Society for Paediatric Endocrinology consensus guidelines on screening, diagnosis, and management of congenital hypothyroidism. Horm Res Paediatr. 2014;81(2):80-103. https://doi.org/10.1159/000358198.

8. van Wassenaer AG, et al. Ten-year follow-up of children born at< 30 weeks' gestational age supplemented with thyroxine in the neonatal period in a randomized, controlled trial. Pediatrics. 2005;116(5):e613-8.

9. van Wassenaer-Leemhuis A, Ares S, Golombek S, Kok J, Paneth N, Kase et al. Thyroid hormone supplementation in preterm infants born before 28 
weeks gestational age and neurodevelopmental outcome at age 36 months. Thyroid. 2014;24(7):1162-9. https://doi.org/10.1089/thy.2013.0618.

10. Ng SM, Turner MA, Michael Weindling A. Neurodevelopmental outcomes at 42 months after thyroxine supplementation in infants below 28 weeks' gestation: a randomized controlled trial. Thyroid. 2020;30(7):948-54. https:// doi.org/10.1089/thy.2019.0293.

11. LaFRANCHI STEPHEN. Thyroid function in the preterm infant. Thyroid. 1999; 9(1):71-8. https://doi.org/10.1089/thy.1999.9.71

12. Williams F, Hume R. The measurement, definition, aetiology and clinical consequences of neonatal transient hypothyroxinaemia. Ann Clin Biochem. 2011;48(1):7-22. https://doi.org/10.1258/acb.2010.010174.

13. Gamma L, Edmund F, et al. Transient hypothyroxinemia of prematurity. Neoreviews. 2016;17(7):e394-402. https://doi.org/10.1542/neo.17-7-e394.

14. Wassenaer $V$, Aleid $G$, et al. Thyroid function in very preterm infants: influences of gestational age and disease. Pediatr Res. 1997;42(5):604-9. https://doi.org/10.1203/00006450-199711000-00009.

15. Williams FLR, Ogston SA, van Toor H, Visser TJ, Hume R. Serum thyroid hormones in preterm infants: associations with postnatal illnesses and drug usage. J Clin Endocrinol Metab. 2005;90(11):5954-63. https://doi.org/10.121 0/jc.2005-1049.

16. Zung A, Bier Palmon R, Golan A, Troitzky M, Eventov-Friedman S, Marom R, et al. Risk factors for the development of delayed TSH elevation in neonatal intensive care unit newborns. J Clin Endocrinol Metab. 2017;102(8):3050-5. https://doi.org/10.1210/jc.2017-00701.

17. Jobe AH, Bancalari E. Bronchopulmonary dysplasia. Am J Respir Crit Care Med. 2001;163(7):1723-9. https://doi.org/10.1164/ajrccm.163.7.2011060.

18. Hamrick SEG, Sallmon H, Rose AT, Porras D, Shelton EL, Reese J, et al. Patent ductus arteriosus of the preterm infant. Pediatrics. 2020;146(5):e20201209. https://doi.org/10.1542/peds.2020-1209.

19. Inder TE, Perlman JM, Volpe JJ. Preterm intraventricular hemorrhage/ posthemorrhagic hydrocephalus. Volpe's Neurology of the Newborn Elsevier. 2018:637-98. https://doi.org/10.1016/B978-0-323-42876-7.00024-7.

20. International Committee for the Classification of Retinopathy of Prematurity. The international classification of retinopathy of prematurity revisited. Arch Ophthalmol (Chicago, III: 1960). 2005;123(7):991-9.

21. Burton GJ, Jauniaux E. Pathophysiology of placental-derived fetal growth restriction. Am J Obstet Gynecol. 2018;218(2):S745-61. https://doi.org/10.101 6/j.ajog.2017.11.577.

22. Battaglia FC, Lubchenco LO. A practical classification of newborn infants by weight and gestational age. J Pediatr. 1967;71(2):159-63. https://doi.org/10.1 016/S0022-3476(67)80066-0.

23. Williams FLR, et al. Transient hypothyroxinemia in preterm infants: the role of cord sera thyroid hormone levels adjusted for prenatal and intrapartum factors. J Clin Endocrinol Metab. 2005;90(8):4599-606. https://doi.org/10.121 0/jc.2005-0214.

24. Liu C, et al. Small for gestational age is a risk factor for thyroid dysfunction in preterm newborns. BMC Pediatr. 2020;20:1-7.

25. Bagnoli $F$, et al. Altered thyroid function in small for gestational age newborns: study based on screening test for congenital hypothyroidism. J Pediatr Sci. 2010;2(4)

26. Bagnoli $\mathrm{F}$, et al. Thyroid function in small for gestational age newborns: a review. J Clin Res Pediatr Endocrinol. 2013;5, 2(Suppl 1).

27. Orbak Z, Akin $Y$, Varoğlu E, Tan H. Serum thyroid hormone and thyroid gland weight measurements in protein-energy malnutrition. J Pediatr Endocrinol Metab. 1998;11(6):719-24. https://doi.org/10.1515/jpem.1998.11.6. 719 .

28. Kumar S, Nadkarni J, Dwivedi R. Thyroid hormone status in malnourished children. Indian Pediatr. 2009;46(3).

29. Lerner RK, Gruber N, Pollak U. Congenital heart disease and thyroid dysfunction: combination, association, and implication. World J Pediatr Congenit Heart Surg. 2019;10(5):604-15. https://doi.org/10.1177/215013511 9857704.

30. Olivieri A, Stazi MA, Mastroiacovo P, Fazzini C, Medda E, Spagnolo A, et al. A population-based study on the frequency of additional congenital malformations in infants with congenital hypothyroidism: data from the Italian registry for congenital hypothyroidism (1991-1998). J Clin Endocrinol Metab. 2002;87(2):557-62. https://doi.org/10.1210/jcem.87.2.8235.

31. Yaqoob M, Manzoor J, Hyder SN, Sadiq M. Congenital heart disease and thyroid dysfunction in Down syndrome reported at Children's Hospital, Lahore, Pakistan. Turk J Pediatr. 2019;61(6):915-24. https://doi.org/10.24953/ turkjped.2019.06.013
32. Lee HJ, et al. Clinical course of infants with congenital heart disease who developed thyroid dysfunction within 100 days. Ann Pediatr Endocrinol Metab. 2017;22(4):253

33. Carrascosa A, Ruiz-Cuevas P, Clemente M, Salcedo S, Almar J. Thyroid function in 76 sick preterm infants 30-36 weeks: results from a longitudinal study. J Pediatr Endocrinol Metab. 2008;21(3):237-44. https://doi.org/10.151 5/jpem.2008.21.3.237.

34. Malik S, Cleves MA, Zhao W, Correa A, Hobbs CA, and the National Birth Defects Prevention Study. Association between congenital heart defects and small for gestational age. Pediatrics. 2007;119(4):e976-82. https://doi. org/10.1542/peds.2006-2742.

35. Ades A, Johnson BA, Berger S. Management of low birth weight infants with congenital heart disease. Clin Perinatol. 2005;32(4):999-1015. https:// doi.org/10.1016/j.clp.2005.09.001.

36. Fisher, Delbert A. "Thyroid system immaturities in very low birth weight premature infants." Semin Perinatol. 32. 6. WB Saunders, 2008.

37. Chung HR, Shin CH, Yang SW, Choi CW, Kim BI, Kim EK, et al. High incidence of thyroid dysfunction in preterm infants. J Korean Med Sci. 2009: 24(4):627-31. https://doi.org/10.3346/jkms.2009.24.4.627.

38. Moon S, Kim J. lodine content of human milk and dietary iodine intake of Korean lactating mothers. Int J Food Sci Nutr. 1999;50(3):165-71. https://doi. org/10.1080/096374899101201.

39. Woo HC, Lizarda A, Tucker R, Mitchell ML, Vohr B, Oh W, et al. Congenital hypothyroidism with a delayed thyroid-stimulating hormone elevation in very premature infants: incidence and growth and developmental outcomes. J Pediatr. 2011;158(4):538-42. https://doi.org/10.1016/j.jpeds.201 0.10 .018 .

40. den Berghe V, Greet F d Z, Lauwers P. Dopamine suppresses pituitary function in infants and children. Crit Care Med. 1994;22(11):1747-53. https:// doi.org/10.1097/00003246-199422110-00008.

41. Daneman D, Holzman IR, White C, Foley TP. Effects of exchange transfusion on neonatal thyroid function. J Pediatr. 1981;98(3):482-4. https://doi.org/10.1 016/S0022-3476(81)80730-5.

42. Das BK, Agarwal P, Agarwal JK, Mishral OP. Serum cortisol and thyroid hormone levels in neonates with sepsis. Indian J Pediatr. 2002:69(8):663-5. https://doi.org/10.1007/BF02722699.

43. Cuestas RA, Engel RR. Thyroid function in preterm infants with respiratory distress syndrome. J Pediatr. 1979;94(4):643-6. https://doi.org/10.1016/ S0022-3476(79)80042-6.

44. Filippi L, Pezzati M, Poggi C, Rossi S, Cecchi A, Santoro C. Dopamine versus dobutamine in very low birthweight infants: endocrine effects. Arch Dis Child Fetal Neonatal Ed. 2007;92(5):F367-71. https://doi.org/10.1136/adc.2 006.098566 .

\section{Publisher's Note}

Springer Nature remains neutral with regard to jurisdictional claims in published maps and institutional affiliations.

Ready to submit your research? Choose BMC and benefit from:

- fast, convenient online submission

- thorough peer review by experienced researchers in your field

- rapid publication on acceptance

- support for research data, including large and complex data types

- gold Open Access which fosters wider collaboration and increased citations

- maximum visibility for your research: over $100 \mathrm{M}$ website views per year

At $\mathrm{BMC}$, research is always in progress.

Learn more biomedcentral.com/submissions 